SHS Web of Conferences 17, 01018 (2015)

DOI: $10.1051 /$ shsconf/ 20151701018

(C) Owned by the authors, published by EDP Sciences, 2015

\title{
Empirical Research on the Herding in Chinese Securities Investment Fund
}

\author{
Shuyuan Li \\ School of Economics, Shanghai University, Shanghai, 200122, China
}

\begin{abstract}
The securities investment fund is the largest investor in China, and its herding has an important impact on the securities market. This article takes the seasonal data of the open-end fund from the 1 st season in 2010 to the 4th season in 2013 as the sample and uses the corrected LSV model to make an empirical inspection for the herding in Chinese securities investment fund. The result shows that there's a serious herding in Chinese securities investment fund. It is found from the further research that the herding degree has a positive correlation with the securities market fluctuation, so it intensifies the fluctuation in the securities market.
\end{abstract}

Keywords. securities investment; LSV model; empirical inspection

\section{Introduction}

From early 1990s, China started to explore and experience the securities investment fund. In the short 20-year period, the securities investment fund, either in scale or quantity, has realized leap frog development. By the end of 2013, China has approved the establishment of 74 fund companies, with totally 1,552 managed funds, 3,118.080 billion shares in total and 3,002.424 billion yuan of total net value of assets management. Theoretically, the securities investment fund shall have the "concentrated investment, separated risk and expert financing". But in our special national conditions, the securities investment fund always presents a herding like an individual investor to go for rise and prevent itself from decline. As an important research subject in the behavior finance, the herding always draws attention from people. Scharfstein and Stein (1990) ${ }^{1}$ thought when the investment manager of funds makes decision, it may ignore its own conditions and judgment and turn to follow other managers' decisions, which indicates a reputation-type herding. Bikhchandani, Hirshleifer and Welch $(1992)^{2}$ proposed a sequential herding model to indicate the investor may have the herding when it is in the sequential decision due to the uncertainty of information. Qi Xiang and Zhao Yong $(2009)^{3}$ studied the herding based on Evolutionary Game, and through the establishment and analysis of the replicator dynamic model, they found the herding is a rational selection.

In the domestic research, many scholar used the LSV method to measure the herding of Chinese securities investment fund in different periods. They concluded there's a herding in Chinese securities investment fund, but their empirical data had a huge difference. Yunlong Yang, Wenhu He (2013) ${ }^{4}$ established GARCH model to make an empirical analysis on the herding in Chinese curb transaction market from 2009 to 2012. It was found from the research that the degree of herding in Chinese curb transaction market is low. Zhaoxia Yan, Caixia Yan $(2013)^{5}$ used CCK 
model to make an empirical research on the herding in Chinese stock market, and found the herding will be more obvious in the rising process of stock market. This article will use the latest market data to make an empirical research on the herding in the securities investment fund.

\section{Model selection}

Lakonishok, Shleifer and Vishny $(1992)^{6}$ proposed the LSV model and it was widely used to inspect the herding degree. Its principle is to compare the average transaction probability of the fund to a set of stocks with the average transaction probability of the fund to the same set of stocks if there's no herding, then it discovered the mutual imitation degree of fund when it is in a transaction. This measurement is actually to inspect the relevance of transaction behavior of securities investment fund with the trend of selling the same stocks. The original expression of the original model is described as follows:

$$
H M(i, t)=|P(i, t)-E[P(i, t)]|
$$

Thereafter, there were many scholars that improved this model, and the improvement mostly recognized and widely used is to subtract an adjustment factor after the Formula (1), namely:

$$
H M(i, t)=|P(i, t)-E[P(i, t)]|-E\{|P(i, t)-E[P(i, t)]|\}
$$

According to the research of Zuoyan Huang (2012) ${ }^{7}$, if using Formula (2) to calculate the herding degree, the results will contain positive and negative values that will be offset when calculating the overall degree of herding, and the overall herding may be underestimated. So the LSV model was revised as:

$$
H M(i, t)=\| P(i, t)-E[P(i, t)]|-E\{|P(i, t)-E[P(i, t)]|\}|
$$

The overall herding factor in th period is expressed as:

$$
H M(t)=\frac{1}{N} \sum_{i=1}^{N} H M(i, t)
$$

$\mathrm{N}$ refers to the total number of sample stocks in th period.

Wermers $(1999)^{8}$ further refined LSV model and proposed the concept of buyer herding and seller herding, expressed as:

$$
\begin{aligned}
& B H M(i, t)=H M(i, t), \text { when } P(i, t)>E[P(i, t)] \\
& \operatorname{SHM}(i, t)=H M(i, t), \text { when } P(i, t)<E[P(i, t)]
\end{aligned}
$$

This article will use Formula 4 to calculate the overall herding degree of securities investment fund, and use Formula 5 and 6 to respectively calculate the buyer herding degree and seller herding degree.

\section{Sample selection and data treatment}

This article selects the first 10 heavyweight stocks in all the seasonal reports of open-end fund from the 1st season in 2010 to the 4th season in 2013 as the research objectives. The data is sourced from GTA database, and the original data is treated as follows:

(1). Take the data from the first season in 2010 as the basic data, and compare the changes in number of stocks held by the funds in adjacent seasons to determine whether the fund will be the net buyer or net seller of a particular stock;

(2). Only select the stocks with 5 and more than 5 funds involving the transaction for research;

(3). Ignore the changes in number of stocks held by the funds due to stock allocation, stock increase by transfer, stock sent and other factors;

(4). Assume the transaction between funds and stocks is fully completed in one season;

(5). Classify the stocks and transaction direction for each fund in each season and list the number of their buyer funds $B(i, t)$ and seller funds $S(i, t)$. 


\section{Empirical inspection}

\subsection{Inspection of overall herding}

The overall herding degree of all the open-end funds from the 1st season in 2010 to the 4th season in 2013 and the herding degree of buyer and seller are listed in Table 1.

Table 1. Measurement of overall herding of the funds

\begin{tabular}{lllll}
\hline Year & Season & HM & BHM & SHM \\
\hline 2010 & 2 & 0.1479 & 0.1444 & 0.1513 \\
& 3 & 0.1340 & 0.0989 & 0.1778 \\
& 4 & 0.1515 & 0.1676 & 0.1357 \\
\hline 2011 & 1 & 0.1353 & 0.1332 & 0.1370 \\
& 2 & 0.1335 & 0.1232 & 0.1418 \\
& 3 & 0.1267 & 0.1015 & 0.1560 \\
& 4 & 0.1291 & 0.0957 & 0.1631 \\
\hline 2012 & 1 & 0.1237 & 0.1305 & 0.1184 \\
& 2 & 0.1330 & 0.1389 & 0.1272 \\
& 3 & 0.1243 & 0.1377 & 0.1116 \\
& 4 & 0.1184 & 0.1265 & 0.1099 \\
\hline 2013 & 1 & 0.1238 & 0.1454 & 0.1036 \\
& 2 & 0.1164 & 0.1144 & 0.1185 \\
& 3 & 0.1159 & 0.1467 & 0.0900 \\
& 4 & 0.1226 & 0.1283 & 0.1153 \\
\hline Average & & 0.1291 & 0.1288 & 0.1305 \\
\hline
\end{tabular}

The overall herding degree from the 1 st season in 2010 to the 4th season in 2013 is 0.1291 , the overall herding degree of buyer 0.1288 , and of seller 0.1305 which is a little higher than the herding of buyer. In the historical data, the overall herding degree in the fourth season in 2010 is the highest, namely 0.1515 , lowest in the third season in 2013, namely 0.1159 . Lakonishok, Shleifer and Vishny(1992)used LSV method to make an empirical research on the herding in 769 stock funds, of which the overall herding was just 0.027; Wermers (1999) made an empirical inspection on the herding in 2424 American mutual funds, of which the overall herding degree was also just 0.034 . Therefore, the securities investment fund in China has a serious herding degree. A series of Chinese special conditions, such as entrusting agent relation, frequent change of fund manager, lack of incentive and imbalanced assessment system for fund performance, are the main reasons that induce serious herding in the securities investment fund.

\subsection{Classified inspection of herding}

\subsubsection{Classification according to the number of involved funds}


Divide the sample stocks into three classes, namely 5-10 involved funds, 11-30 involved funds and more than 30 involved funds, and respectively calculate the overall herding degree of each class in each season. The results are summarized in Table 4-3.

Table 2. Herding result obtained from classified inspection according to the number of involved funds

\begin{tabular}{|c|c|c|c|c|c|c|c|}
\hline \multirow[b]{2}{*}{ Year } & \multirow{2}{*}{$\begin{array}{l}\text { Seas } \\
\text { on }\end{array}$} & \multicolumn{2}{|c|}{ 5-10 involved funds } & \multicolumn{2}{|c|}{ 11-30 involved funds } & \multicolumn{2}{|c|}{$>30$ involved funds } \\
\hline & & $\begin{array}{l}\text { Number of } \\
\text { samples }\end{array}$ & HM & $\begin{array}{l}\text { Number of } \\
\text { samples }\end{array}$ & HM & $\begin{array}{l}\text { Number of } \\
\text { samples }\end{array}$ & HM \\
\hline \multirow{3}{*}{2010} & 2 & 194 & 0.1523 & 144 & 0.1407 & 46 & 0.1518 \\
\hline & 3 & 199 & 0.1393 & 155 & 0.1267 & 51 & 0.1351 \\
\hline & 4 & 230 & 0.1591 & 161 & 0.1404 & 61 & 0.1520 \\
\hline \multirow{4}{*}{2011} & 1 & 230 & 0.1467 & 151 & 0.1198 & 60 & 0.1304 \\
\hline & 2 & 219 & 0.1411 & 125 & 0.1268 & 62 & 0.1201 \\
\hline & 3 & 231 & 0.1335 & 142 & 0.1218 & 58 & 0.1113 \\
\hline & 4 & 217 & 0.1434 & 136 & 0.1148 & 67 & 0.1117 \\
\hline \multirow{4}{*}{2012} & 1 & 198 & 0.1345 & 145 & 0.1153 & 69 & 0.1106 \\
\hline & 2 & 187 & 0.1475 & 171 & 0.1259 & 70 & 0.1117 \\
\hline & 3 & 203 & 0.1435 & 153 & 0.1038 & 83 & 0.1154 \\
\hline & 4 & 228 & 0.1300 & 139 & 0.1034 & 97 & 0.1127 \\
\hline \multirow{4}{*}{2013} & 1 & 220 & 0.1362 & 157 & 0.1133 & 97 & 0.1125 \\
\hline & 2 & 226 & 0.1333 & 176 & 0.1090 & 103 & 0.0917 \\
\hline & 3 & 229 & 0.1368 & 175 & 0.0946 & 100 & 0.1053 \\
\hline & 4 & 243 & 0.1344 & 164 & 0.1139 & 95 & 0.1074 \\
\hline Average & & & 0.1408 & & 0.1180 & & 0.1187 \\
\hline
\end{tabular}

As shown in the above table, the herding degree for 5-10 involved funds is the highest, namely 0.1408 . The herding is obviously declined as the number of involved funds rises. In the set of stocks with more than 30 involved funds, the herding degree has a little increase compared to the last stocks. Possibly most of the stocks with high number of involved funds are the current hotspot stocks.

\subsubsection{Classification according to the listed ages}

Serious IPO over evaluation is a chronic problem in Chinese securities market. To inspect whether the herding is caused by application for new stocks or the herding in the fund itself. Then we will divide the stocks according to their listed ages to calculate the herding degree in each stage.

As shown in Table 3, all the maximums of overall herding, buyer herding and seller herding appear in a set of stocks with less than one year of listed ages, indicating the concentrated application for new stocks actually intensifies the herding degree. In the set of stocks with 1-5 years, 5-10 years and more than 10 years of listed ages, the herding degree presents an obvious decline but more than $10 \%$, which is still in a high level compared to the empirical result from the foreign countries. It shows the herding in Chinese securities investment fund is actually and will be existent for a long time. 
Table 3. Herding degree obtained after classification according to the listed age

\begin{tabular}{|l|l|l|l|l|}
\hline Herding degree & $<\mathbf{1}$ year & $\mathbf{1 - 5}$ years & $\mathbf{5 - 1 0}$ years & $>$ 10 years \\
\hline HM & 0.1861 & 0.1201 & 0.1190 & 0.1215 \\
\hline BHM & 0.1861 & 0.1217 & 0.1231 & 0.1229 \\
\hline SHM & 0.1905 & 0.1180 & 0.1154 & 0.1201 \\
\hline
\end{tabular}

\subsubsection{Classification according to circulated stock value}

This article selects the circulated stock value to represent the stock scale, and divides the stocks in four seasons in 2013 into three scales, namely small scale (with circulated stock value less than 5 billion yuan), medium scale (with circulated stock value between 5 billion yuan and 30 billion yuan) and large scale (with circulated stock value over 30 billion yuan), which are used to inspect the herding degrees corresponding to respective stocks with different scales. The results are as shown in Table 4-5.

Table 4. Herding degree obtained after classification according to the circulated stock value

\begin{tabular}{|l|l|l|l|l|l|}
\hline $\begin{array}{l}\text { Scale of circulated } \\
\text { stock }\end{array}$ & $\begin{array}{l}\text { Proportion of } \\
\text { stock number }\end{array}$ & HM average & Number & BHM average & SHM average \\
\hline $\begin{array}{l}\text { Less than } 5 \text { billion } \\
\text { yuan }\end{array}$ & $29 \%$ & 0.1339 & 135 & 0.1431 & 0.1158 \\
\hline $5-30$ billion yuan & $55 \%$ & 0.1212 & 261 & 0.1236 & 0.1181 \\
\hline Over 30 billion yuan & $16 \%$ & 0.1041 & 75 & 0.1158 & 0.0949 \\
\hline
\end{tabular}

As shown in Table 4, with the increase of stock scale, either the overall herding or buyer or seller herding will present a declining trend. The herding degree of funds in a stock with large-scale circulated value is the lowest, indicating the company with large-scale stocks also has a large scale in itself; the information disclosure is relatively in time and accurate; there's little noise information in the market; the fund manager may use the information it knows to carry out transactions, with low degree of deliberate mutual imitation.

\subsection{The impact of herding in securities investment fund on the market}

Make a relevance analysis by inputting the yield rates and overall herding degree data for the Shanghai composite index and the Shenzhen component index in each season into Matlab software, and the result is shown as follows, among which Y1 refers to the yield rate of Shanghai composite index, Y2 the yield rate of Shenzhen component index and HM the overall herding degree:

As shown in the above table, the herding in securities investment fund has a positive correlation with the market fluctuation, and it's very obvious. To further confirm the casual relationship between the herding and market fluctuation, we also need the Granger casual relationship inspection, and the result is shown as follows: 
Table 5. Analysis on the relevance of yield rate of Shanghai composite index with HM

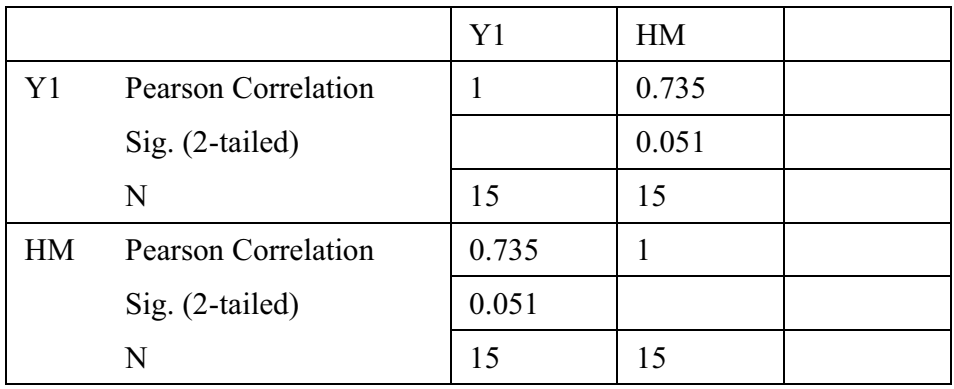

Table 6. Analysis on the relevance of yield rate of Shenzhen component index with HM

\begin{tabular}{|ll|c|c|}
\hline \multirow{2}{*}{ Y2 } & Y2 & HM \\
\hline \multirow{2}{*}{$\begin{array}{l}\text { Sig. (2-tailed) } \\
\text { N }\end{array}$} & 1 & 0.719 \\
\cline { 3 - 4 } & Pearson Correlation & 0.051 \\
\cline { 3 - 4 } & HM & 15 & 15 \\
\cline { 3 - 4 } & Sig. (2-tailed) & 0.719 & 1 \\
\cline { 3 - 4 } & $\mathrm{N}$ & 0.053 & \\
\cline { 3 - 4 } & & 15 & 15 \\
\hline
\end{tabular}

Table 7. Granger casual relationship inspection between HM and the yield rate of Shanghai composite index

\begin{tabular}{llll}
\hline \hline Null Hypothesis: & Obs & F-Statistic & Probability \\
\hline \hline HM does not Granger Cause Y1 & 13 & 3.7347 & 0.0677 \\
Y1 does not Granger Cause HM & & 0.1285 & 0.7925 \\
\hline \hline
\end{tabular}

Table 8. Granger casual relationship inspection between HM and the yield rate of Shenzhen component index

\begin{tabular}{llll}
\hline \hline Null Hypothesis: & Obs & F-Statistic & Probability \\
\hline \hline HM does not Granger Cause Y1 & 13 & 2.6378 & 0.0823 \\
Y1 does not Granger Cause HM & & 0.1924 & 0.6351 \\
\hline \hline
\end{tabular}

As shown in Table 7 and Table 8, the herding of securities investment fund is in positive correlation with fluctuation in securities market, indicating the herding intensifies the fluctuation in securities market and conflicts with the original intention of China to greatly develop the institutional investors.

\section{Conclusion}

This article uses revised LSV model with high flexibility and selects the first 10 heavyweight stocks in all the seasonal reports of open-end fund from the 1st season in 2010 to the 4 th season in 
2013 as the research objectives to make an empirical inspection for the herding in Chinese securities investment fund. It is found from the research:

(1) The overall herding degree is 0.1291 , the overall herding degree of buyer 0.1288 , and of seller 0.1305. The securities investment fund in China has a serious herding degree.

(2) In the set of stocks with 5-10 involved funds, the herding is obviously higher than the other stocks; the herding of securities investment fund is in its highest level in the set of stocks with 1-5 years of listed ages, indicating the securities investment fund has a thought of "go for rise and prevent itself from decline" instead of a long-term and valuable investment; In the set of stocks with circulated stock value more than 30 billion yuan, the herding degree is the lowest. In one hand, the information of large-scale stock is relatively transparent; on the other hand, many largescale stocks belong to income stocks with stable increasing potential. The securities investment fund tends to be selected according to its own investment direction and assets conditions.

(3) The herding of securities investment fund is in positive correlation with fluctuation in securities market, indicating the herding intensifies the fluctuation in securities market.

\section{References}

1. David S.Scharfstein and JEREMY C.Stein, Herd Behavior and Investment [J]. The American Economic Review, 1999, 80(3): 465-479.

2. Bikchandani S., Hirshleifer, D. and Welch I., A Theory of Fads, Fashion, Custom, and Cultural Change as Informational Cascades [J]. Journal of Political Economy, 1992, 100: 992-1026.

3. Qi Xiang and Zhao Yong, Evolutionary Simulation for the Population of Altruist and Egoist in Herd Behavior Model [J]. Systems Engineering, 2009, 29(2): 167-172.

4. Yunlong Yang, Wenhu He. Empirical Research on Chinese Curb Transaction MarketBased on GARCH model [J] Qinghai Finance, 2013(8).

5. Zhaoxia Yan, Caixia Yan. Empirical Research on the Herding in Chinese Stock Market [J]. Business Accounting, 2013(12).

6. Lakonishok J., Shleifer A. and Vishny R. The Impact of Institutional Trading on Stock Prices [J]. Journal of Financial Economics, 1992, 329(1): 23-43.

7. Zuoyan Huang. Research on the Institutional Investor Behavior and Policy Guide [M]. Shanghai: Shanghai University Press, 2012: 117-118.

8. Russ Wermers, Mutual Fund Herding and the Impact on Stock Prices [J]. The Journal of Finance, 1999(2): 581-622. 